\title{
Three-Phase AC-DC Converters with Passive, Active and Hybrid Current Injection Circuits - Part I
}

\author{
M. Rivera ${ }^{\dagger 1}$, D. Faundez ${ }^{\dagger 2}$, J. Kolar*3 ${ }^{* 3}$ P. Wheeler ${ }^{\ddagger 4}$ and J.A. Riveros ${ }^{\dagger 5}$ \\ ${ }^{\dagger}$ Faculty of Engineering, Universidad de Talca \\ Curico, CHILE \\ ${ }^{1}$ marcoriveutalca.cl \\ ${ }^{2}$ dfaundez12@alumnos.utalca.cl \\ ${ }^{5}$ jriveros@utalca.cl \\ ${ }^{*}$ ETH Zurich \\ Zurich, SWITZERLAND \\ ${ }^{3}$ kolarelem.ee.ethz.ch \\ ${ }^{\ddagger}$ The University of Nottingham \\ Nottingham, UK \\ ${ }^{4}$ Pat. Wheeler@nottingham.ac.uk
}

\begin{abstract}
AC-DC three-phase converters are very well known for having enhanced power quality with unity displacement power factor, low total harmonic pollution on the AC side, and controllable DC output with unidirectional or bidirectional power flow. The first part of this paper presents a review of several three-phase AC-DC converters with passive current injection circuits, detailing their respective topologies and characteristics.
\end{abstract}

Resumen- Los convertidores trifásicos CA-CC son muy conocidos por tener una calidad de potencia mejorada con factor de desplazamiento unitario del factor de potencia, baja distorsión armónica total en el lado de CA y salida CC controlada con flujo de potencia unidireccional o bidireccional. La primera parte de este artículo presenta una revisión de varios convertidores trifásicos $\mathrm{CA}-\mathrm{CC}$ con circuitos de inyección de corriente pasiva, detallando sus respectivas topologías y características.

\section{INTRODUCTION}

Three-phase AC-DC diode converter are extendedly used because they are very simple and affordable, but at the expenses of input currents highly distorted and low displacement power factor. In order to solve these issues, different topologies have been proposed [1]. Passive filters, active filters and current controlled injection are common techniques to externally attenuate the current harmonics generated by rectifiers.

Passive filters are connected between the rectifier and supply terminals (in series or shunt) to block or direct to ground the current harmonics generated by the rectifier. Series filters cause high impedance at the current harmonic frequencies. They may cause distortion to the rectifier input voltage harmonics, at the cost of physical size and components. Shunt filters are parallel connected at the connection point of the supply and rectifier, creating a low impedance at the current frequencies and the harmonics tend to flow towards the supply neutral through the shunt filter rather than through the supply. This filter only takes a small percentage of the full line current and the combination of the supply impedance with that of the filter can cause resonances that might affect the behavior of the rectifier or the supply.

Active filters supply either current or voltage harmonics on the AC side which are of equal amplitude and opposite phase to these generated by the non-linear load of the rectifier. It is widely used in industrial power systems and requires measurements of voltage and current waveforms. Suitable isolation should be provided.

Hybrid power filters correspond to combinations of active and passive filters. They were developed to overcome the above disadvantages and make active filtering methods more attractive from an economical and viability point of view.

Current control injection techniques involve the injection of a constant pattern variable amplitude current on the AC side of standard line commutated rectifiers to reduce the line current harmonics generated by the rectifiers.

AC-DC systems with improved source current quality could be developed as high-switching-frequency rectifiers systems or as passive multi-pulse rectifiers allowing an effective control of the output voltage and input side [2].

One solution is to include an extra converter (boost, buck, and buck-boost) which handle all the energy circulating through the converter, showing a good performance in different operation points (Fig. 1). The main problem of this alternative is that a costly controller is needed, and in addition, the efficiency is reduced because all the power is handled by the extra converter.

Another alternative is to replace the extra converter by a passive network as depicted in Fig. 1. This configuration does not process all the energy circulating through the converter but at the cost of huge passive elements reducing its efficiency. Additionally, the components of the passive network are adapted for a sole operation point, thus the accomplishment of the converter is not good enough under different load variations. To improve the source current, a special transformer is required in the injection network. As it will be shown later, it is possible to find different three- 


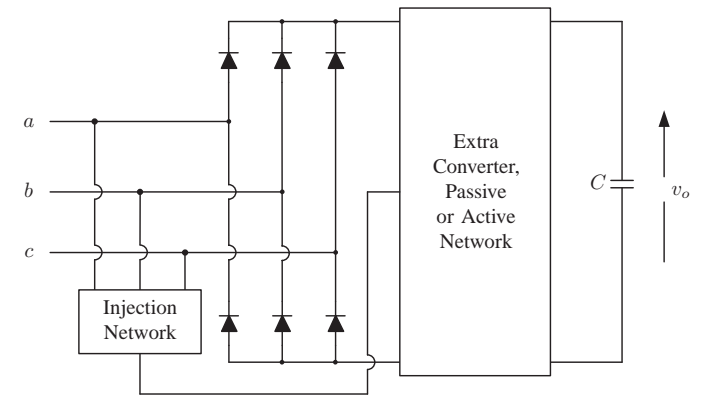

Fig. 1. Three-phase rectifier with extra converter, passive or active network

phase rectifiers using these passive networks with different transformer configurations.

Recently an active network (which requires an inductor operating at high switching frequency) has been proposed to replace the passive network (Fig. 1), allowing for improved efficiency and fast dynamic response to different operation points. Similarly to the passive network, in this architecture the power processing is reduced. The injection network consists of three bi-directional switches to select the path of the inductor current to be added to the corresponding phase.

Finally, it is possible to find also some hybrid combinations of active networks where an injection network is formed for a special transformer. In this paper, these different topologies will be presented.

\section{Three-Phase Rectifier With Passive Network}

\section{A. 12-Pulse Rectifier Using a Double-Wound Transformer}

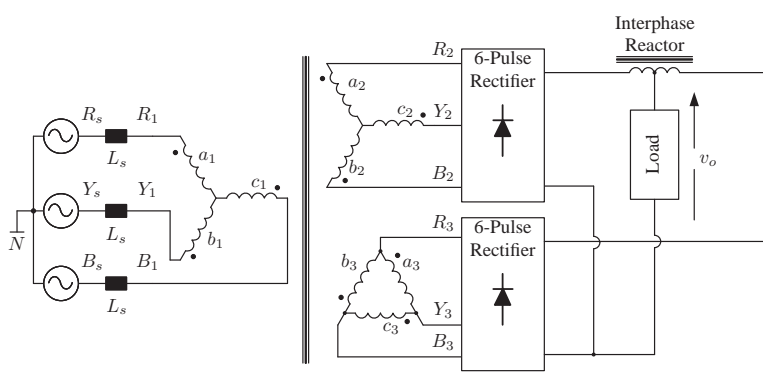

Fig. 2. 12-pulse rectifier using a double-wound transformer

The converter consists of two six-pulse rectifiers connected by means of Y- $\Delta$ and Y-Y isolation transformers, obtaining a $30^{\circ}$ phase shift [3] (Fig. 2). This connection naturally mitigates the 5th and 7th harmonics in the source currents. The outputs are connected to the load using an interphase reactor. The use of a double-wound transformer constitutes the main disadvantage of the power converter, which normally is large and heavy.

\section{B. 12-Pulse Rectifier Using an Autotransformer}

The topology shown in Fig. 3, is a current source converter which is utilized in aircrafts to add AC-DC conversion [4]-[6]. This configuration allows to reduce the magnetic component and rectifier weights at the cost of eliminating the galvanic isolation obtaining a converter with less cost and higher efficiency. In this converter two interphase reactors are needed to have autonomous operation of each six-pulse rectifier. With this adjustment the rectifier diodes operate with a displacement of $120^{\circ}$ per cycle, naturally mitigating the 5th and 7th harmonics from the source currents. The same current sharing is obtained with the autotransformer array, which conducts to equal leakage reactance in series with each line of the rectifier bridges.

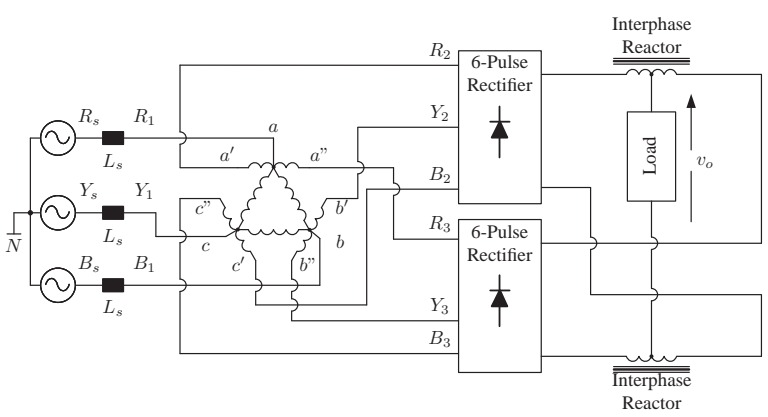

Fig. 3. 12-pulse rectifier with an autotransformer

\section{12-Pulse Rectifier Using a Transformer Primary in Se-} ries

This converter connects the transformer primaries in series with the bottom rectifier [3]. The secondary delta windings feed the top rectifier. The transformer is rated at approximately half of the total power but the circuit does not have galvanic isolation. The topology is a current-fed/voltagesource multi-pulse rectifier. The output side of the bridge rectifiers are linked to a single DC capacitor, obtaining a 12-pulse voltage waveform at the rectifier inputs (Fig. 4).

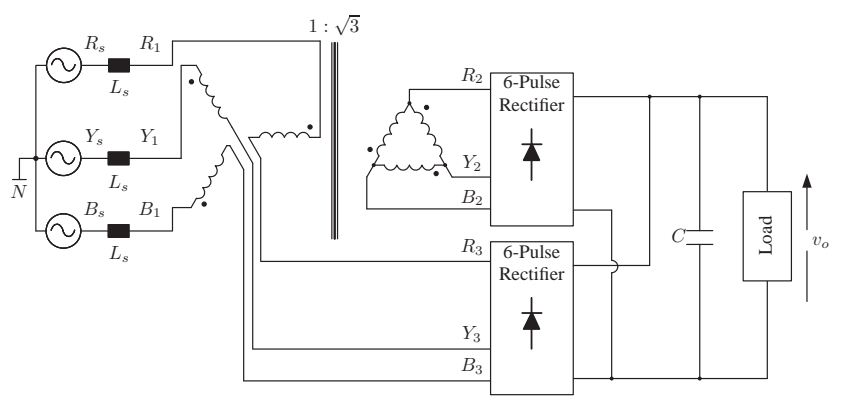

Fig. 4. 12-pulse rectifier using a transformer primary in series

D. 18-Pulse Diode Rectifier Using an Autotransformer and Winding Configuration of Interphase Reactor
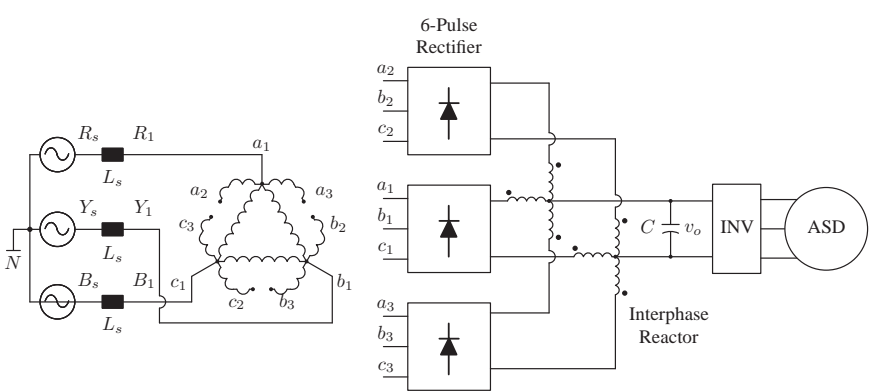

Fig. 5. 18-pulse diode rectifier using an autotransformer and winding configuration of interphase reactor

There are different 18-pulse converter circuits to be employed in future aircraft. The power circuit is a current 
source and the basic topology does not require an interphase transformer (Fig. 5). At any time, one rectifier keeps inactive because the bridges do not share load current. Therefore, the diodes need to support the full load current and they must be designed to accomplish this requirement [4], [5].

The concept of the 12-pulse rectifier with an autotransformer is extended to an 18-pulse configuration using three six-pulse diode rectifier. With this new arrangement, the 5th, 7 th, 11 th and 13th harmonics are completely mitigated in the source current.

\section{E. 24-Pulse Rectifier with Passive Ripple Injection}

In this circuit (Fig. 6) the injection diode-bridge is considered in a series connection with the main rectifiers and the injection transformer is situated between the split DClink and the injection diode-bridge [7]. Because of the series connection, the same current is mandatory in each rectifier, and due to the series inductance in the principal circuit, these currents are treated as current-fed. The rectifier input voltage waveforms are similar to those produced by a 24-pulse rectifier. But, the injection diodes are exposed to the full load current due to the series connection of the injector with the rectifiers. The converter uses only passive components. In addition, this topology operates with fewer components than other AC-DC converters with analogous achievement. The injection circuit is based on a single-phase transformer with a single-phase full bridge rectifier, used to produce a square wave voltage at six times the source frequency, providing an extra voltage level. In aerospace applications, a converter with reduced weight and size is mandatory. Therefore, just one of the rectifiers is directly filled by the principal transformer. Among the input and output sides of the converter there is no active isolation and thus the load voltage cannot be controlled by the transformer turns-ratio [8], [9].

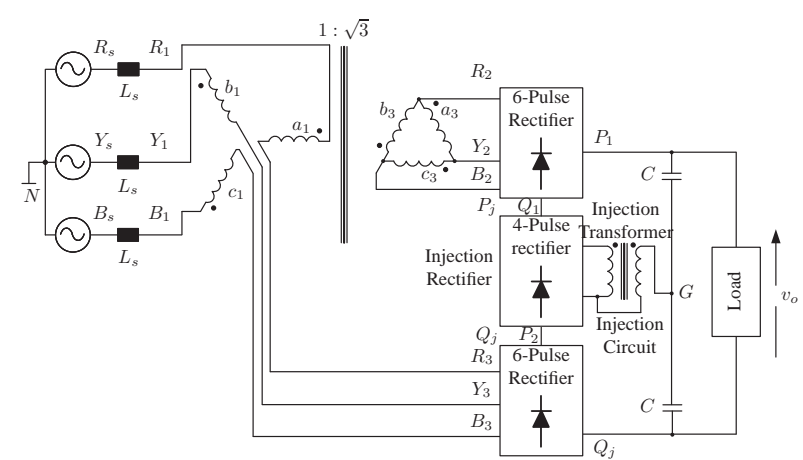

Fig. 6. 24-pulse rectifier with passive ripple injection

\section{F. 24-Pulse Current-Source-Converter Using a Current Rip- ple Injector in Series with the Load}

The current-source 24-pulse circuit (Fig. 7) is formed by a 12-pulse converter and a ripple injection circuit in series with a high inductance load, producing an almost constant load current [10].

Ripple injection circuits typically include four switches and a small injection transformer to the 12-pulse rectifier. This additional circuit modifies the behavior by either current or voltage injection at six times the supply frequency

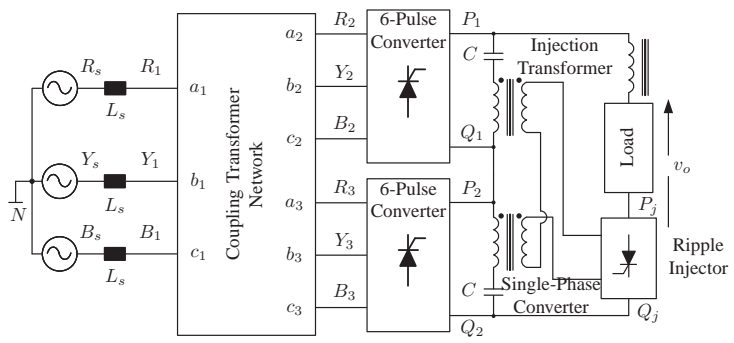

Fig. 7. 24-pulse current-source-converter using a current ripple injector in series with the load

to modify the current ripple waveform through the injection transformer, which is connected between the mid-point of the rectifiers, two DC blocking capacitors and a single-phase converter bridge.

\section{G. 24-Pulse Diode Rectifier with a Tapped Interphase Transformer}

The converter (Fig. 8) is almost the same as the classical 12-pulse topology but with an adjusted transformer structure and the two diodes linked to a distinctively tapped interphase transformer (Fig. 9), which is used as part of the injector circuit [11]-[13]. The secondary windings of the input transformer are designed in spread delta. This configuration allows balanced sets of three-phase voltages with $30^{\circ}$ phasedisplacement for the diode rectifiers, providing the same leakage reactance in series with the rectifiers. The diodes are switched in a natural mode by the inherent six-pulse voltage ripple of the rectifiers, producing 24-pulse current waveforms at both rectifier input and output. The configuration exhibits a power characteristic with 5th, 7th, 11th, 13th, 17 th, and 19th harmonic deleted from the source currents.

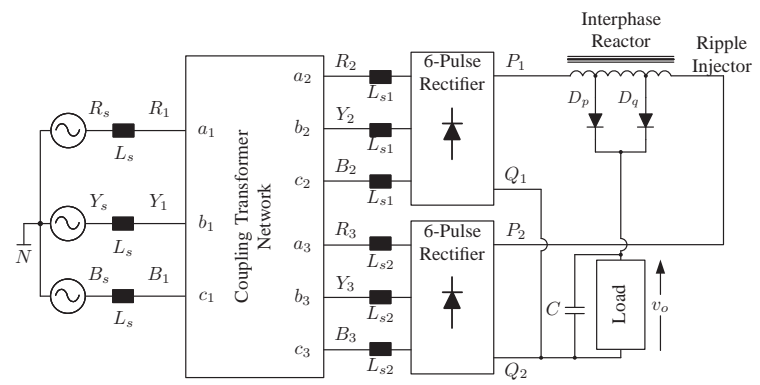

Fig. 8. 24-pulse diode rectifier with a tapped interphase transformer

$$
\text { Network }
$$

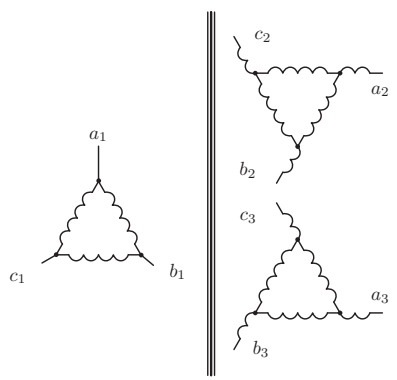

Fig. 9. Coupling transformer network of the 24-pulse diode rectifier 


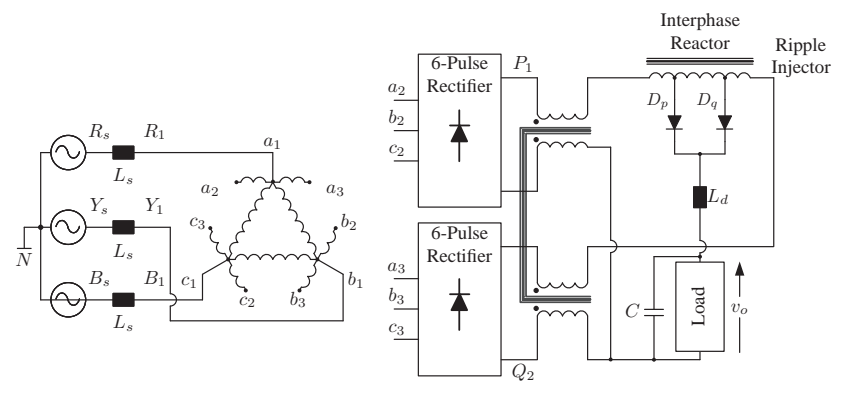

Fig. 10. 24-pulse rectifier with zero sequence blocking transformer (ZSBT)

\section{H. 24-Pulse Rectifier with Zero Sequence Blocking Trans- former (ZSBT) (Fig. 10)}

The configuration requires one Zero Sequence Blocking Transformer (ZSBT) to have autonomous action of the two 6-pulse diode rectifiers [14]-[17]. It shows high impedance to zero sequence currents, rising in $120^{\circ}$ conduction for each diode and the same current distribution in the load side. An interphase reactor tapped appropriately to realize pulse doubling is associated at the output of the ZSBT. The two load voltages of the rectifier are equal but with a phase displacement of $30^{\circ}$ (necessary for 12-pulse action), containing ripple of six times the line frequency.

\section{Harmonic Reducing 24-Pulse Rectifier}

The rectifier consists of the conventional series connected 12-pulse diode rectifier with a simple additional circuit which is formed by 4 diodes, 2 auto-transformers and 2 capacitors [18], as shown in Fig. 11. This topology allows for an efficient, economical and reliable alternative to accomplish uncontrolled high DC power and high voltage from the network without harmonic distortion.

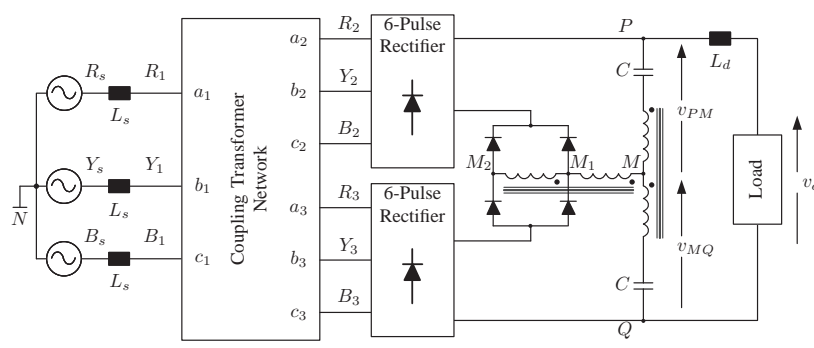

Fig. 11. 24-pulse rectifier with auxiliary circuit (harmonic reducing)

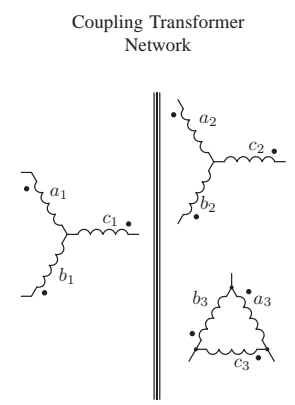

Fig. 12. Coupling transformer network of the 24-pulse rectifier with auxiliary circuit (harmonic reducing)

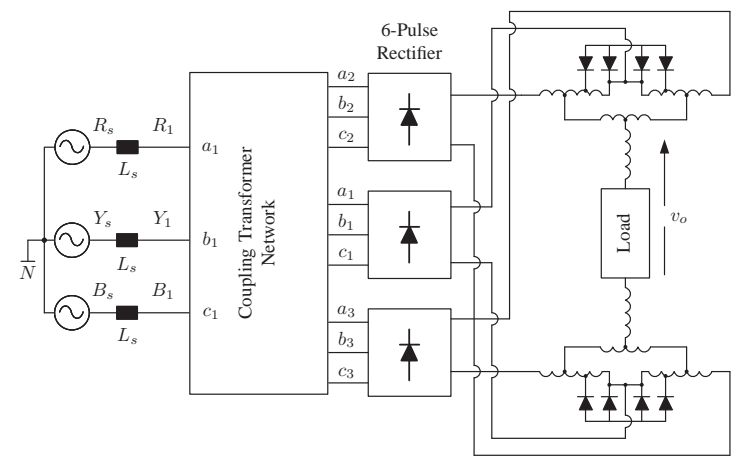

Fig. 13. Three-phase rectifier with a passive 28-step current shaper

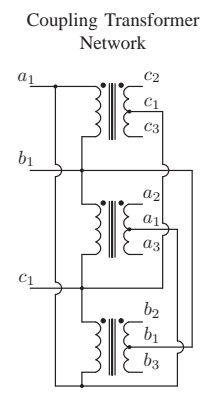

Fig. 14. Coupling transformer network of the three-phase rectifier with a passive 28-step current shaper

\section{J. Three-Phase Rectifier with a Passive 28-Step Current Shaper}

The converter shown in Fig. 13, is formed by a phaseshifting transformer, 3 six-pulse diode rectifiers, and 6 interphase transformers [19]. The phase-shifting transformer generates in addition 2 sets of three-phase voltage sources from the original three-phase input. On the primary side, a three-phase transformer is linked in delta with three-phase input voltages and three $90^{\circ}$ phase-displacement voltages are induced on the secondary side. Two interphase transformers are used to obtain a 28-step sinusoidal waveform (Fig. 14).

\section{K. 24-Pulse Current-Source-Converter Using an Inter- Phase Reactor as Part of the Ripple Injector}

The converter shown in Fig. 15, is a parallel 12-pulse configuration including two six-pulse converters and a thyristortapped interphase reactor, which is used as part of the injection circuit [20], [21]. The tapping thyristors operates at six-times the source frequency obtaining input and output waveforms comparable to those of a 24-pulse converter, obtaining minimal current THD. The potential of the circulating ripple frequency is filled back to the DC scheme via the interphase reactor which works as an autotransformer.

\section{36-Pulse Voltage-Source-Converter Using the Voltage Ripple Injection Method Applied to the 12-Pulse Converter in Parallel}

This is a 36-pulse circuit (Fig. 16) that is formed by a double-bridge self-switched voltage source converter, adjusted with an interphase reactor (used as the injection transformer) and a GTO-diode single-phase bridge to produce a multilevel waveform [22]. This ripple injection scheme includes less switches, smaller capacitor size and no unbalanced problems in the capacitors. 


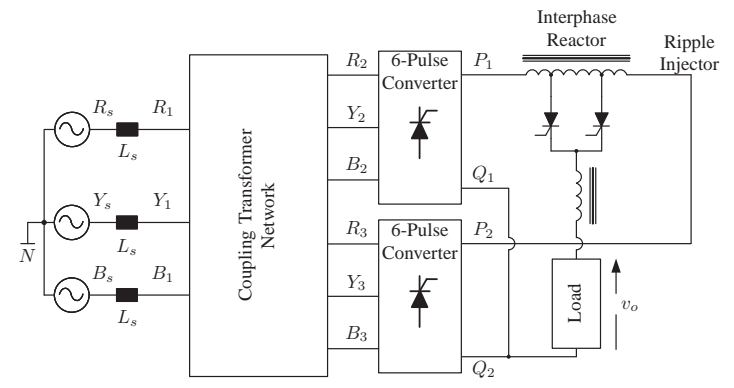

Fig. 15. 24-pulse current-source-converter using an inter-phase reactor as part of the ripple injector

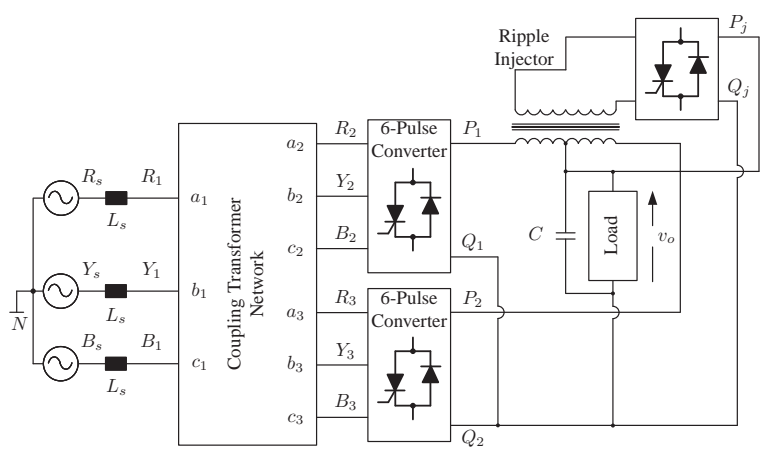

Fig. 16. 36-pulse voltage-source-converter using the voltage ripple injection method applied to the 12-pulse converter in parallel

\section{36-Pulse Voltage-Source-Converter Using the Voltage} Ripple Injection Method Applied to the 12-Pulse Converter in Series

This circuit has an injection transformer which is connected between the split DC-link and the mid-point of the converter (Fig. 17). The transformer turns-ratio is designed in such a way that a minimum line current is produced [23], [24].

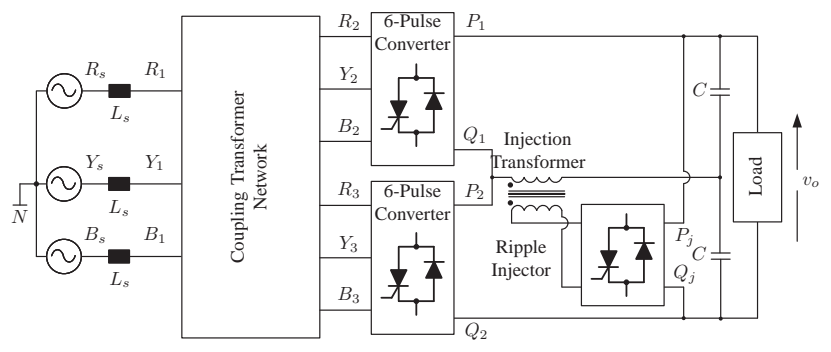

Fig. 17. 36-pulse voltage-source-converter using the voltage ripple injection method applied to the 12-pulse converter in series

\section{N. 36-Pulse Converter with Coupling Transformer Network}

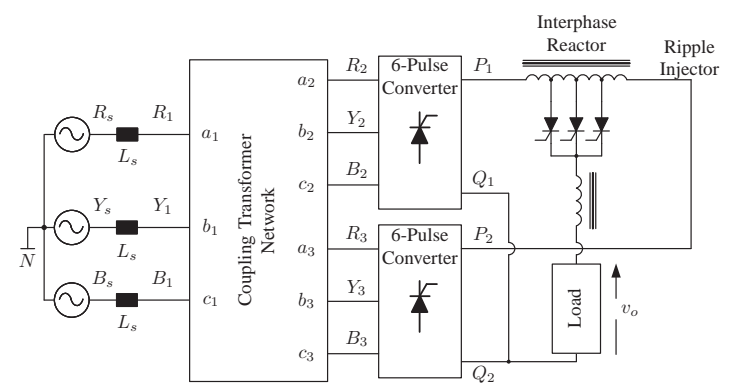

Fig. 18. 36-pulse converter with coupling transformer network

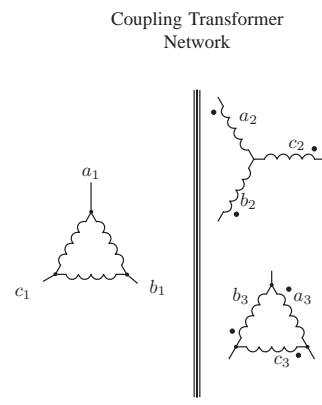

Fig. 19. Coupling transformer network of the 36-pulse converter

The converter shown in Fig. 18, works with 36-pulses and can operate as a rectifier for a DC load or as an intermediate stage for an inverter [25]-[28]. A highly sinusoidal current at both ends of the system (rectifier input and inverter output) is obtained. In addition, a notable reduction of the transfer of abnormal harmonics is achieved by the reduction of DClink harmonics due to the 36-pulse configuration. Finally, this higher pulsation deletes the necessity of filtering at the rectifier end as well as mitigating problems at the inverter end.

\section{O. Multi-Pulse Self-Commutated Current Source Rectifier}

The converter shown in Fig. 20, is based on the reinjection of multilevel DC current pulses via a GTO or IGCT switched multi-tapped interphase reactor. The interface transformer (Fig. 21) turns ratios are formed as $k_{n}: 1$ (primary to secondary) for the $\mathrm{Y}$ connection and $k_{n}: \sqrt{3}$ for the $\Delta$ connection. There is no need for passive filtering in order to obtain practically sinusoidal currents [29], [30].

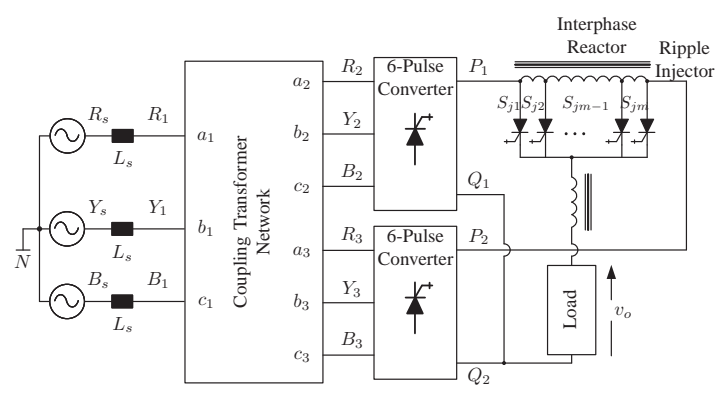

Fig. 20. Multi-pulse self-commutated current-source-rectifier

$$
\begin{aligned}
& \text { Coupling Transformer } \\
& \text { Network }
\end{aligned}
$$

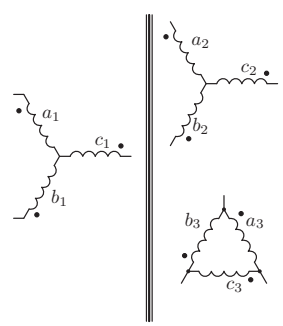

Fig. 21. Coupling transformer network for the multi-pulse re-injection converter

\section{P. General Configuration for Pulse Multiplication in Series- Connected Converters}

This general configuration is obtained by including an additional circuitry to a classic power converter connection 
[31], [32]. It is basically a traditional converter structure with a re-injection circuit which handles the pulse multiplication. In this multiplication circuitry a factor of 2 involves a bridge, a factor of 3 involves one bridge and a thyristor, a factor of 4 involves 2 bridges (also another secondary winding in transformer), a factor of 5 involves two bridges and a thyristor, and so on (Fig. 22 to Fig. 26).

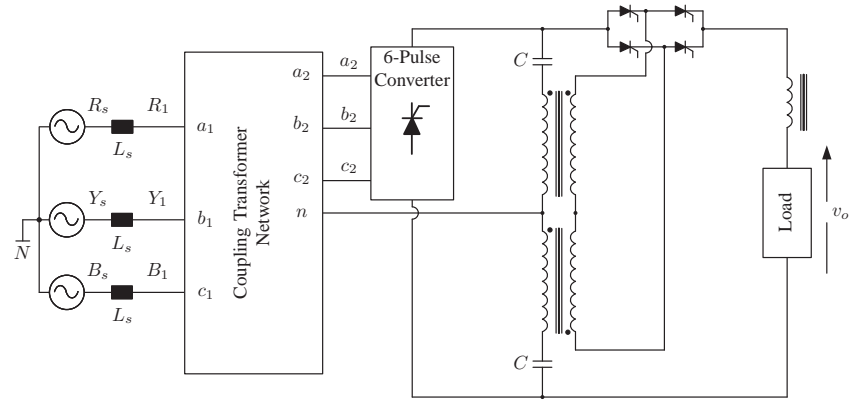

Fig. 22. Circuit configuration of the 6 to 12-pulse converter

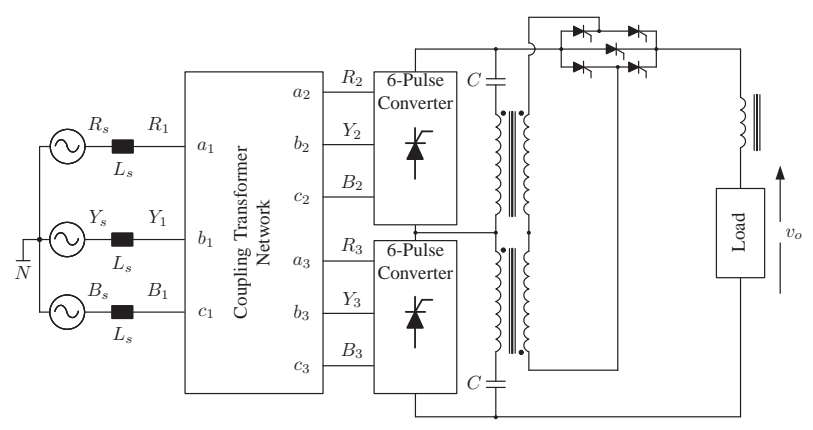

Fig. 23. Circuit configuration of the 12 to 36-pulse converter

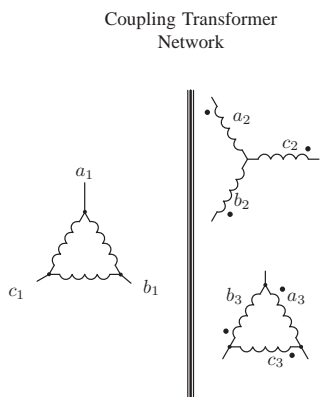

Fig. 24. Coupling transformer network of the 12 to 36-pulse converter

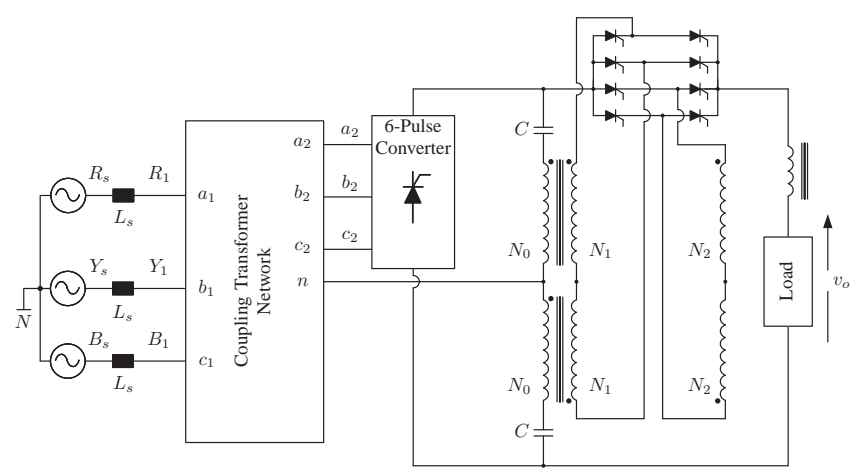

Fig. 25. Circuit configuration of the 6 to 24-pulse converter

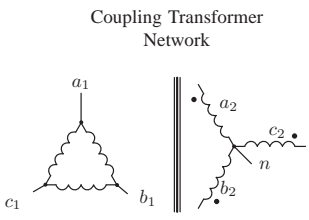

Fig. 26. Coupling transformer network of the 6 to 12-pulse and 6 to 24-pulse converter

\section{CONCLUSION}

In the first part of this paper, the most popular and well known three-phase AC-DC power converters with passive current injection circuits have been presented. As it has been shown, six-pulse diode converters are highly inexpensive but at the expenses of high harmonic pollution in the source currents. In order to improve these currents, passive networks use transformers which also add size and weight to the converter.

\section{ACKNOWLEDGMENT}

The authors would like to thank the financial support of FONDECYT Regular 1160690 and Postdoctoral 3170014 Research Projects as well as MEC Project 80150056.

\section{REFERENCES}

[1] N. Vazquez, H. Rodriguez, C. Hernandez, E. Rodriguez, and J. Arau, "Three-phase rectifier with active current injection and high efficiency," Industrial Electronics, IEEE Transactions on, vol. 56, no. 1, pp. 110-119, 2009.

[2] J. Kolar and H. Ertl, "Status of the techniques of three-phase rectifier systems with low effects on the mains," in Telecommunication Energy Conference, 1999. INTELEC '99. The 21st International, 1999, pp. 16 pp.-.

[3] D. Paice, "Power electronics converter harmonics:multipulse methods for clean power," Wiley-IEEE Press Ebook Chapters, 1996.

[4] S. Choi, A. Von Jouanne, P. Enjeti, and I. Pitel, "Polyphase transformer arrangements with reduced kva capacities for harmonic current reduction in rectifier type utility interface," in Power Electronics Specialists Conference, 1995. PESC '95 Record., 26th Annual IEEE, vol. 1, 1995, pp. 353-359 vol.1.

[5] S. Choi, P. Enjeti, and I. Pitel, "Polyphase transformer arrangements with reduced kva capacities for harmonic current reduction in rectifier-type utility interface," Power Electronics, IEEE Transactions on, vol. 11, no. 5, pp. 680-690, 1996.

[6] T. Clark, F. Chivite-Zabalza, A. Forsyth, and M. Barnes, "Analysis and comparison of diode rectifier units suitable for aerospace applications," in Power Electronics, Machines and Drives, 2008. PEMD 2008. 4th IET Conference on, 2008, pp. 602-606.

[7] F. Chivite-Zabalza, A. Forsyth, and D. Trainer, "A simple, passive 24-pulse ac-dc converter with inherent load balancing," Power Electronics, IEEE Transactions on, vol. 21, no. 2, pp. 430-439, 2006.

[8] F. Chivite-Zabalza, A. Forsyth, and I. Araujo-Vargas, "36-pulse hybrid ripple injection for high-performance aerospace rectifiers," Industry Applications, IEEE Transactions on, vol. 45, no. 3, pp. 992-999, 2009.

[9] — "36-pulse hybrid ripple injection for high performance aerospace rectifiers," in Power Electronics and Drive Systems, 2007. PEDS '07. 7th International Conference on, 2007, pp. 591-598.

[10] J. Arrillaga and M. Villablanca, "24-pulse hvdc conversion," Generation, Transmission and Distribution, IEE Proceedings C, vol. 138, no. 1, pp. 57-64, 1991.

[11] S. Choi, P. Enjeti, and D. Paice, "New 24-pulse diode rectifier systems for utility interface of high power ac motor drives," in Applied Power Electronics Conference and Exposition, 1996. APEC '96. Conference Proceedings 1996., Eleventh Annual, vol. 2, 1996, pp. 925-931 vol.2.

[12] S. Choi, B. Lee, and P. Enjeti, "New 24-pulse diode rectifier systems for utility interface of high-power ac motor drives," Industry Applications, IEEE Transactions on, vol. 33, no. 2, pp. 531-541, 1997.

[13] S. Choi, J. Oh, K. Kim, and J. Cho, "A new 24-pulse diode rectifier for high voltage and high power applications," in Power Electronics Specialists Conference, 1999. PESC 99. 30th Annual IEEE, vol. 1, 1999, pp. 169-174 vol.1. 
[14] B. Singh, G. Bhuvaneswari, and V. Garg, "Scott-connected autotransformer based multipulse ac-dc converters for power quality improvement in vector controlled induction motor drives," in Power Electronics and Drives Systems, 2005. PEDS 2005. International Conference on, vol. 2, 2005, pp. 1491-1496.

[15] — "Power-quality improvements in vector-controlled induction motor drive employing pulse multiplication in ac-dc converters," Power Delivery, IEEE Transactions on, vol. 21, no. 3, pp. 1578-1586, 2006.

[16] B. Singh, G. Bhuvaneswari, V. Garg, and S. Gairola, "Pulse multiplication in ac-dc converters for harmonic mitigation in vector-controlled induction motor drives," Energy Conversion, IEEE Transactions on, vol. 21, no. 2, pp. 342-352, 2006.

[17] B. Singh, V. Garg, and G. Bhuvaneswari, "Polygon-connected autotransformer-based 24-pulse ac-dc converter for vector-controlled induction-motor drives," Industrial Electronics, IEEE Transactions on, vol. 55, no. 1, pp. 197-208, 2008.

[18] Y. Nishida and M. Nakaoka, "A new harmonic reducing three-phase diode rectifier for high voltage and high power applications," in Industry Applications Conference, 1997. Thirty-Second IAS Annual Meeting, IAS '97., Conference Record of the 1997 IEEE, vol. 2, 1997, pp. $1624-1632$ vol.2.

[19] C.-L. Chen and G.-K. Horng, "A new passive 28-step current shaper for three-phase rectification," Industrial Electronics, IEEE Transactions on, vol. 47, no. 6, pp. 1212-1219, 2000.

[20] J. Arrillaga, "A modified parallel hvdc converter for 24 pulse operation," Power Engineering Review, IEEE, vol. 11, no. 1, pp. 501991.

[21] J. Arrillaga and M. Villablanca, "A modified parallel hvdc convertor for 24 pulse operation," Power Delivery, IEEE Transactions on, vol. 6 , no. 1, pp. 231-237, 1991.

[22] Y. Liu, J. Arrillaga, and N. Watson, "Multi-level voltage sourced conversion by voltage reinjection at six times the fundamental frequency," Electric Power Applications, IEE Proceedings -, vol. 149, no. 3, pp. 201-207, 2002.

[23] _ "A new high-pulse voltage-sourced converter for hvdc transmission," Power Delivery, IEEE Transactions on, vol. 18, no. 4, pp. 1388-1393, 2003.

[24] Y. Liu, J. Arrillaga, and N. R. Watson, "A new high-pulse voltagesourced converter for hvdc transmission," Power Engineering Review, IEEE, vol. 22, no. 12, pp. 65-65, 2002.

[25] M. Villablanca, W. Ziehlmann, C. Flores, C. Cuevas, and P. Armijo, "Harmonic reduction in adjustable-speed synchronous motors," Power Engineering Review, IEEE, vol. 21, no. 8, pp. 55-55, 2001.

[26] _ "Harmonic reduction in adjustable-speed synchronous motors," in Power Engineering Society Winter Meeting, 2002. IEEE, vol. 2, 2002, pp. 1231 vol.2-

[27] — "Harmonic reduction in adjustable-speed synchronous motors," Energy Conversion, IEEE Transactions on, vol. 16, no. 3, pp. 239245, 2001

[28] M. Villablanca, J. Abarca, C. Cuevas, A. Valencia, and W. Rojas, "Adjustable speed synchronous motors. i. system harmonic reduction," in Industry Applications Conference, 1999. Thirty-Fourth IAS Annual Meeting. Conference Record of the 1999 IEEE, vol. 3, 1999, pp. 1988-1993 vol.3.

[29] L. Perera, Y. Liu, N. Watson, and J. Arrillaga, "Multi-level current reinjection in double-bridge self-commutated current source conversion," Power Delivery, IEEE Transactions on, vol. 20, no. 2, pp. 984 991, 2005.

[30] J. Arrillaga, Y. Liu, L. Perera, and N. Watson, "A current reinjection scheme that adds self-commutation and pulse multiplication to the thyristor converter," Power Delivery, IEEE Transactions on, vol. 21, no. 3, pp. 1593-1599, 2006.

[31] M. Villablanca, M. Arias, and C. Acevedo, "High-pulse series converters for hvdc systems," Power Delivery, IEEE Transactions on, vol. 16, no. 4, pp. 766-774, 2001.

[32] — "High-pulse series converters for hvdc systems," Power Engineering Review, IEEE, vol. 21, no. 8, pp. 64-64, 2001. 